\title{
Estimation of Traffic Delay Due to U-Turns at Uncontrolled Medians: Case Study in Phnom Penh, Cambodia
}

\author{
Maksat Omarov ${ }^{1, *(\mathbb{D}}$, Syuhaida Ismail ${ }^{1}\left(\mathbb{D}\right.$, Wan Nurul Mardiah Wan Mohd Rani ${ }^{1}$ and Serdar Durdyev ${ }^{2}$ (D) \\ 1 Razak Faculty of Technology and Informatics, Universiti Teknologi Malaysia, Kuala Lumpur 54100, Malaysia; \\ syuhaida.kl@utm.my (S.I.); wnurul.kl@utm.my (W.N.M.W.M.R.) \\ 2 Department of Engineering and Architectural Studies, Ara Institute of Canterbury, \\ Christchurch 8011, New Zealand; durdyevs@ara.ac.nz \\ * Correspondence: omaksat2@graduate.utm.my
}

check for updates

Citation: Omarov, M.; Ismail, S.; Rani, W.N.M.W.M.; Durdyev, S. Estimation of Traffic Delay Due to U-Turns at Uncontrolled Medians: Case Study in Phnom Penh, Cambodia. Sustainability 2022, 14, 118. https:/ / doi.org/10.3390/su14010118

Academic Editor: Elżbieta Macioszek

Received: 8 November 2021

Accepted: 18 December 2021

Published: 23 December 2021

Publisher's Note: MDPI stays neutral with regard to jurisdictional claims in published maps and institutional affiliations.

Copyright: (c) 2021 by the authors Licensee MDPI, Basel, Switzerland. This article is an open access article distributed under the terms and conditions of the Creative Commons Attribution (CC BY) license (https:// creativecommons.org/licenses/by/ $4.0 /)$.

\begin{abstract}
Lack of infrastructure capacity to the demand in mobility results in delays in traffic. U-turns restrict the movement of the opposing through-traffic during the maneuver, hence triggering delays. Significant delays can be observed, especially in high volume traffic, where U-turning is not restricted. Hence, it is imperative to study the delays incurred by the U-turning vehicles to assess their impacts on traffic congestion. This study thus proposes a quantitative method to estimate the aggregate and average delay per vehicle caused by U-turns at uncontrolled medians of urban roads. Traffic data were collected at a corridor where vehicles were allowed to U-turn on a four-lane divided mixed traffic urban road in Phnom Penh, Cambodia. The delay in the opposing lane of traffic was calculated by analyzing the data using a novel analytical method; a derivative of the Webster's delay model. The results reveal that the suggested technique evaluates the caused delay with good accuracy. Excessive traffic delay and about three seconds delay per vehicle in the through-traffic of the opposite lane align well with the experienced delay at the site. The method can be used to assess the delay at straight corridor sections where U-turns are not restricted, understand the causes of the delay, and develop control measures for improved traffic performance.
\end{abstract}

Keywords: traffic delay estimation; congestion; traffic flow; U-turn; Phnom Penh; Cambodia

\section{Introduction}

The rapid urbanization and extension in the reach of supply chains has led to increasing demand on transportation services [1]. Despite its socio-economic benefits, such as providing mobility for people and freight, the transportation sector has also been responsible for a severe impact on the environment [2]. Reportedly, the following environmental impacts are attributed to the transportation sector: increase in $\mathrm{CO}_{2}$ emissions $(15 \%$ globally), air and noise pollution, contamination of the hydrographic systems, contamination, and erosion of soil, as well as deforestation [3]. This study investigates the added urban congestion due to U-turn maneuvers in straight corridors of Phnom Penh city, Cambodia. In turn, it allows for better understanding of the extra $\mathrm{CO}_{2}$ emissions caused by congestion.

Similar to many major cities of developing countries, Phnom Penh is experiencing traffic congestion at extreme levels [4,5]. As such, traffic congestion has been reported, in addition to others, as one of the significant contributors to air pollution in the city. One of the many reasons for the excessive delays, and therefore congestion, is the interruptions caused in the flow of traffic by U-turning vehicles at medians [6]. U-turning maneuvers can impede the flow of through-traffic on the opposing lanes, thus causing delays and congestion [7]. The maneuver, when performed on roads with low traffic volume, causes minimal interruption and therefore is permissible. However, when traffic volumes are high, it is almost impossible for U-turning vehicles to find a clear space in the opposite traffic to do the maneuver. Consequently, in most high-volume traffic, the scenarios involving U-turning vehicles result in impeded flows causing undesired delays. 
There seems to be a lack of quantitative research assessing the delay caused by U-turning vehicles. Most previous research involving U-turn maneuvers were performed to analyze various other aspects of the maneuver and/or under low traffic volumes, which are favorable conditions for the movement. The maneuver's influence on congestion in high volume traffic has not been thoroughly studied. In many developing countries where traffic volumes are high and traffic rules do not exempt U-turning, like on many roads in Phnom Penh, U-turning locations tend to experience significant levels of traffic delay [7-10]. To understand the impacts of the maneuver on traffic congestion, it is important to adopt an effective technique to quantitatively assess the extent of the delay caused by U-turns. This study thus suggests a new methodology to evaluate the aggregate and average delay per vehicle as a result of U-turns at uncontrolled medians of urban roads.

The U-turning maneuver is ubiquitous on most of the roads in Phnom Penh, Cambodia [6]. Although some main intersections restrict the movement, many corridors have passages allowing U-turning. The maneuver not only affects the vehicles immediately next to the turning vehicle, but the majority of the vehicles travelling on the road are observed to experience delay to some extent. The technique developed in this study allows quantitative assessment of the cumulative delay caused by the U-turning vehicles as well as the delay experienced by each vehicle in the opposite traffic.

\section{Literature Review}

Many researchers dedicated their efforts to studying the operational performance of U-turning vehicles at medians, such as analyzing the capacity of the turning vehicles or developing design alternatives to allow for better performance. Mohapatra et al. [8] worked to develop a methodology for identifying the conflict zones for U-turning vehicles at uncontrolled median openings on urban roads under mixed traffic conditions. They reported that the capacity of the U-turn depends on the amount of conflicting traffic, which is also the function of the type of the vehicle making the U-turn. Esawey and Sayed [9], on the other hand, analyzed the operational performance of U-turns at medians with an unconventional design that was newly adopted in Cairo, Egypt. They found that the new median design that they analyzed offered advantages only at very low traffic volumes and showed significant delays when the demand was high. More recently, Mohanty et al. [10] assessed the delay at median openings due to U-turning movement. The researchers findings indicate that vehicles moving at the outer lanes face more delay compared to the vehicles moving in the lanes adjacent to the median. They also suggest that no significant delay difference is observed due to the type of U-turning vehicles.

Some of the studies related to U-turns at intersections reported the influence of the maneuver on the traffic flow. Pirdavani et al. [11] drew attention to the decreased efficiency of an arterial road due to the high demand in U-turns and proposed a new geometric design with a raised island to isolate the movement from the rest of the traffic. Other studies investigated the influence of the U-turning maneuver on the flow rate and capacity of signalized intersections [12-14]. Most of these studies used statistical correlations to develop to adjustment factors that help in estimating the capacity reduction due to the presence of U-turning vehicles at signalized intersections.

The literature discussing the traffic delay due to U-turning vehicles at medians is rather limited. A possible cause for this is the fact that the U-turning maneuver interrupts the flow of traffic so much so that it is only practiced in less advanced traffic systems. The most relevant study found in the literature by Mohanty and Dey [7] analyses the delay caused by the U-turning vehicles at uncontrolled median openings. Site video data from a few median openings in urban roads of India were used to estimate the traffic delay. Regression models were developed to correlate the delay faced by the through-traffic under limited priority conditions. Despite sharing similarities, the study reports significantly lower delay values than that of this study. Moreover, the technique adopted in the Mohanty and Dey study is based on empirical correlations. 
More recently, there were research efforts to study the delay in traffic through machine learning techniques [15-17]. Although these attempts may offer more advanced simulation of the traffic conditions and, therefore, more accurate estimation of the delay, the results may be significantly influenced by the techniques employed in the studies. Until a more universal approach is adopted by the consensus of researchers, the bias in the development of the methodology may limit the potential of the technique.

This study proposes an approach that would fill the gap in the literature in estimating the delay caused by U-turning vehicles at uncontrolled medians with a theoretical background. Based on the Webster's delay model, a new method is developed to analyze the aggregate delay due to median openings and the caused per-vehicle delay. The method explains the mechanism behind the delay and its implications to congestion.

\section{Methodology}

\subsection{Delay Model Due to U-Turn}

Traffic delay is the additional time spent to travel that occurs due to interruptions in the flow of traffic [18]. To assess the delay due to U-turns, a new derivative model of the Webster's delay model [19], based on similar analytical analogy, was developed. Webster's model is used to analyze the delay at intersections, whereas the delay in this paper refers to the additional time that vehicles spend due to the U-turning vehicles impeding the traffic flow on the opposite lanes. Like the Webster's model, the total delay, measured in veh $\cdot h$ or veh $\cdot s$, is given by the area between the arrival and departure curves in a cumulative plot (see Figure 1).

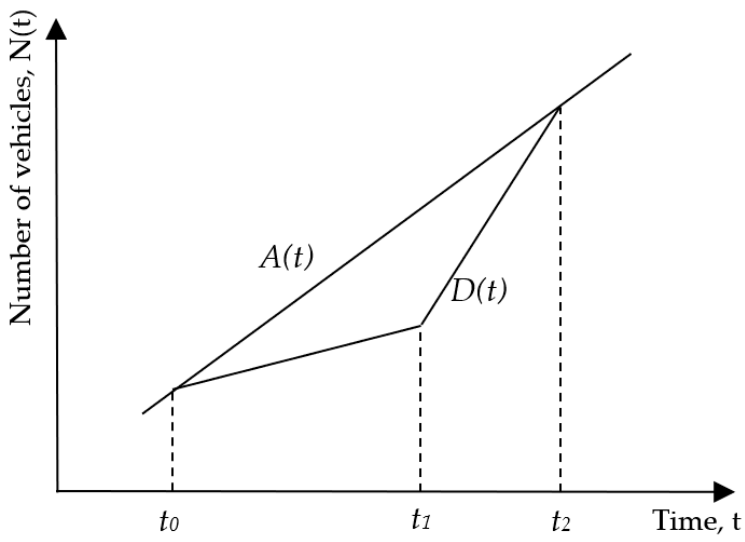

Figure 1. Representation of a delay scenario using a cumulative plot.

Arrival curve in a cumulative plot, $A(t)$, shows the arrival pattern of vehicles on the upstream, whereas the departure curve, $D(t)$, represents vehicles leaving the location in the downstream of the location. Cumulative plots are used in the analysis of the traffic conditions involving flow through restrictions along a travelway [20]. These include interruption in the traffic flows, such as (i) bottlenecks; (ii) construction zones (iii) accident locations and (iv) signalized intersections where the traffic signal interrupts the flow during specific intervals. Cumulative plots can also be used to analyze the delay due to U-turns, since a similar interruption of flow on the opposite lanes is caused by the U-turning vehicle during the maneuver.

The difference between the arrival and the departure curves at any given instance in cumulative graphs shows the number of vehicles not being able to pass through the restricted section. Consequently, the area encompassed by the arrival and departure curves illustrates the magnitude of the delay before the queued vehicles at the section are cleared. In Figure $1, t_{0}$ represents the beginning of the restriction in the flow of traffic, hence the departure rate is lower than the arrival rate; $t_{1}$ is the time when the restriction is lifted, and therefore the departure rate increases to free flow rate; and $t_{2}$ shows the time when all queued vehicles due to the delay are dissipated. 
Mathematically, the delay caused by the impediment of the flow by a single U-turning vehicle, $D_{s}$, can be estimated by the area of the triangular area between the arrival and departure curves [20]. Therefore, the delay in Figure 1 can be calculated using Equation (1):

$$
D_{s}(\text { veh } \times s)=\int_{t 0}^{t 2}[A(t)-D(t)] d t
$$

The solution of Equation (1) requires knowledge about the arrival pattern, $A(t)$, and the departure characteristics of vehicles, $D(t)$, on the opposite lanes during a U-turning maneuver. The rate of arrival, $q_{A}(t)$, can be calculated by the traffic volume per time on the opposite lane. The upstream flow was observed to be relatively steady during the study periods. Departure rates, $q_{D}(t)$, during U-turns drop to very low values (almost to zero), as illustrated in Figure $2 \mathrm{a}, \mathrm{b}$ and recover soon after the impeding vehicle corrects its course on the opposite lane and makes the road available again to the through traffic. It is, therefore, reasonable to assume that (i) no departure occurring between times $t_{0}$ to $t_{1}$, and (ii) the departure rate increasing to about twice the arrival rate (free flow rate) after the road is cleared. These assumptions cover the majority of the U-turning cases reasonably well, and they serve an important role in developing the model to measure the delay.

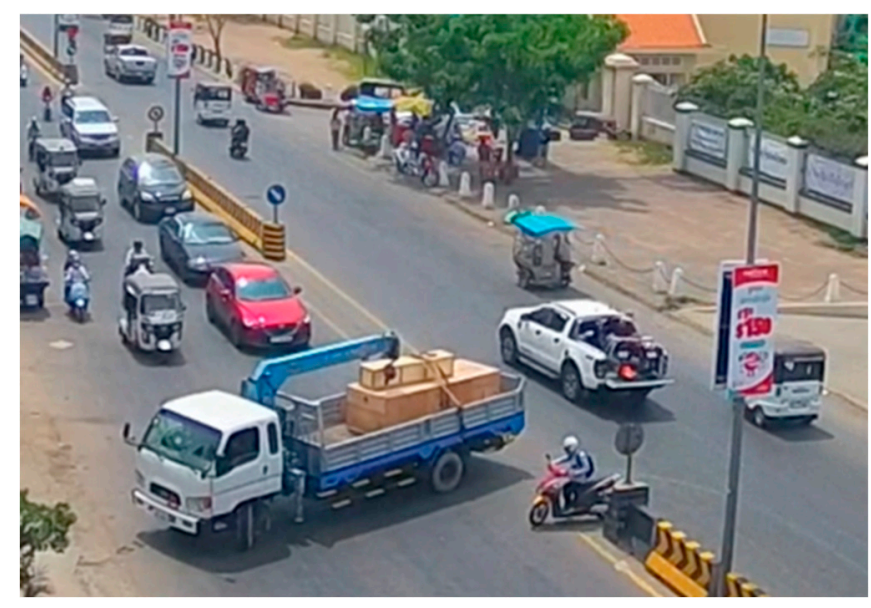

(a)

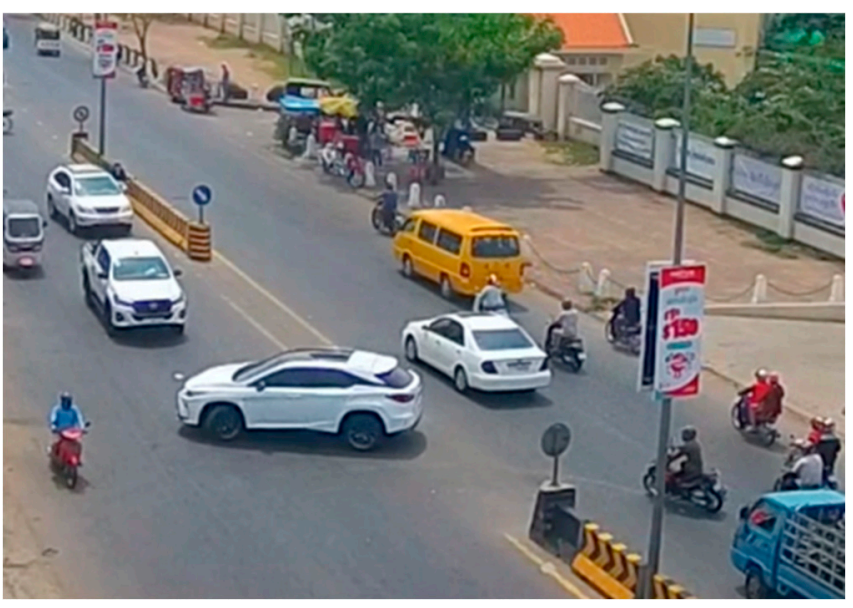

(b)

Figure 2. (a) A truck impeding the traffic on the opposite lanes while U-turning; (b) A car halting the movement on the opposite lanes while U-turning.

With these assumptions, the delay due to a single U-turning vehicle, Equation (1), can be simplified and rewritten as:

$$
D_{s}(v e h \times s)=q_{A} \times t_{U}^{2}
$$

where $q_{A}$ is the arrival rate on the opposite lanes, and $t_{U}$ is the average duration of the U-turning maneuver. Hence, the delay in an hour for each vehicle type, $D_{i}$, can be calculated as:

$$
D_{i}(v e h \times s)=\left(D_{s}\right)_{i} \times f_{i}
$$

where $f_{i}$ represents the U-turn frequency of each type vehicle. The total delay, TD, can therefore be written as:

$$
T D(v e h \times s)=0.25 \times D_{2 w}+D_{3 w}+D_{c a r}+D_{t r}
$$

The coefficient of 0.25 is used for two wheelers due to the lower influence of the two-wheelers on the flow of traffic [21]. Dividing the total delay, $T D$, by the adjusted traffic volume, $V_{a d j}$, gives the delay experienced by each vehicle, delay/vehicle, travelling through the U-turning section on the opposite lanes. 


\subsection{Limitations of the New Model}

The proposed new model should only be used to evaluate the total and per vehicle delay in traffic conditions similar to the studied case. The delay estimated applies only for the traffic travelling on the opposite lane. The impediment of the U-turns on the lanes where the maneuver is initiated is not covered by this technique. It is imperative to understand the assumptions introduced in Equation (2) which apply for all U-turning maneuvers covered in this model. Although realistic in practice, slight variations are to be expected in the actual delay versus the theoretical model due to these assumptions.

\section{Data Collection}

\subsection{Study Location}

A site with the following features was sought for this study: (i) a straight corridor urban road, (ii) mixed traffic with divided median, and (iii) available uncontrolled U-turns at the median. A four-lane divided road section of the Yothapol Khemarak Phoumin boulevard in Khan Boeng Keng Kang district was chosen as it offered the needed environment. The study site was a $75 \mathrm{~m}$ long straight section in front of the Khmer Soviet Friendship Hospital (see Figure 3). The median of the road was divided with concrete blocks with openings for U-turning. The opening on the eastern side had higher U-turn frequencies as it was the first opening for vehicles approaching from the east side. Therefore, the delay analysis in this paper were carried for U-turning vehicles arriving to the median opening from the eastbound.
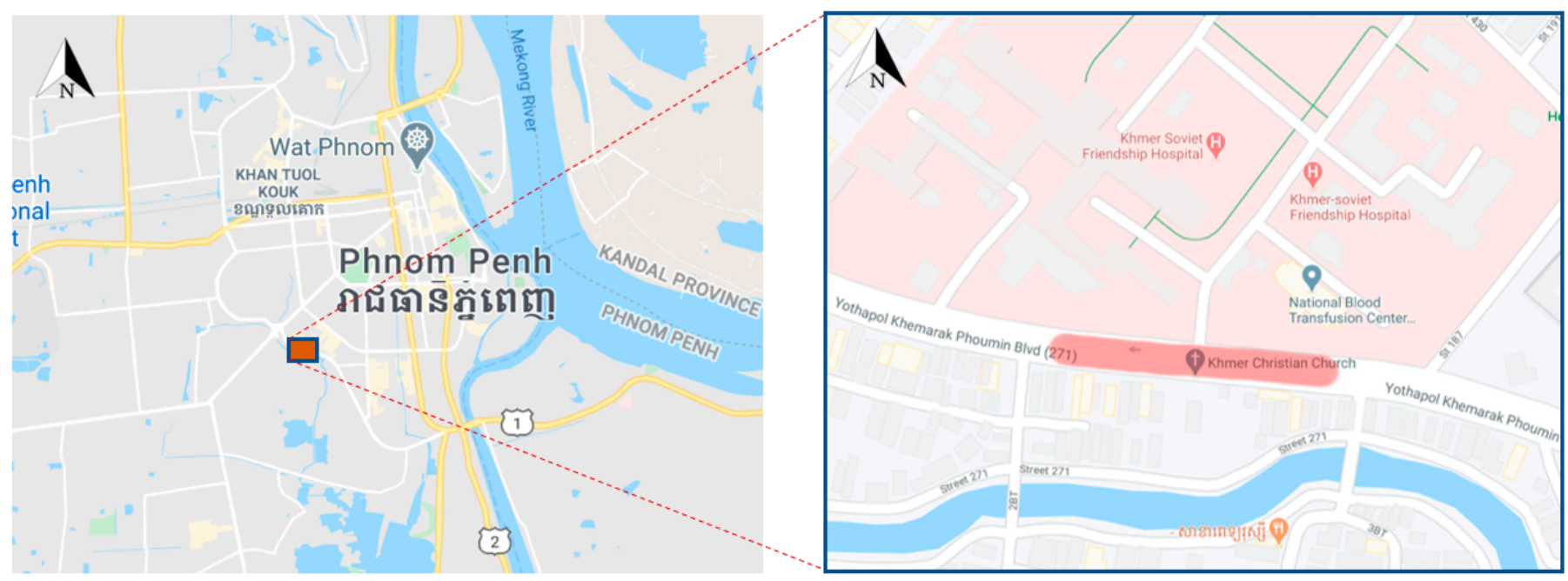

Figure 3. The study site is a straight section (marked in red) on Yothapol Khemarak Phoumin Boulevard.

Motorized vehicles were analyzed under four categories as two-wheelers ( $2 \mathrm{w}$-typical two-wheelers, e.g., Honda Dream), three-wheelers (3w-also locally known as tuktuks, some are modified motorbikes with carriages), cars (passenger cars, e.g., Toyota Camry) and trucks (pickup trucks, e.g., Toyota Hilux, or single-unit trucks). An overhead camera was set up at a distance from an angle that made it possible to collect the required parameters at the study site. The following operation parameters were targeted to be extracted from the recorded videos: the type and frequency of the U-turning vehicles at the specified location; traffic volume and tally of the types of the vehicles; and the mean speed of the traffic during the data collection. Four sets of recordings were conducted in the month of April 2020. The traffic was recorded during non-peak traffic hours, 10 a.m. to noon and 1 p.m. to 3 p.m., to reduce the noise in data due to other factors causing congestion. It should be noted that the traffic conditions were affected by the ongoing COVID-19 pandemic. The volumes observed were lower compared to non-pandemic times. The lower volumes further reduced the noise, allowing for better isolated analysis of the delay, which, under higher volumes, would have not been ideal. 
The video clips were recorded at $1280 \times 720$ resolution and analyzed at a rate of 60 frames per second. The QuickTime multimedia software developed by Apple Inc was employed to evaluate the recorded videos. The software conveniently enables viewing the clips at various speeds, smooth backwards and forwards navigation, as well as pausing and zooming at frames, all of which were used extensively throughout the generation of the data. Since the traffic flow rate was generally high, the operation parameters were collected from slowed motion clips on a case by case basis. The data collected from the video clips were organized and stored on an Excel spreadsheet document.

\subsection{The Geometric Features of the Analyzed Median Opening}

The analyzed section of the road is a four-lane straight corridor with a concrete block divider on the median. The section where the study was conducted is a $22 \mathrm{~m}$ opening in the median without the blocks where U-turning is allowed. The lanes are $3.2 \mathrm{~m}$ wide with faded traffic lines delineating the lanes. No separate island nor an elevation is provided for U-turning vehicles. Figure 4 provides an illustration of the section.

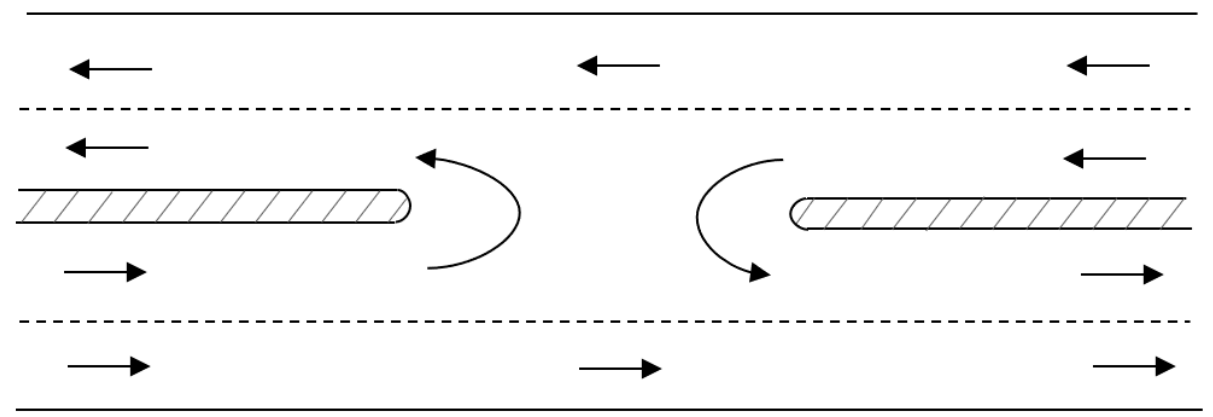

Figure 4. Schematic of the studied median opening on the Yothapol Khemarak Phoumin Boulevard.

\subsection{U-Turn Times}

The U-turn maneuver of each vehicle type was studied separately. Each maneuver was closely analyzed to determine the time it takes to complete the turn. The duration of the maneuver was considered from the time the vehicle starts slowing down to the time when the vehicle catches up with the speed of the traffic on the opposite lane, minus the waiting time of the vehicle to find a clear space in the flow to allow for the maneuver. Notation $t_{U}$ was used to indicate the U-turning times. After closely observing more than 150 motorbikes, 90 three wheelers, 70 cars and 25 trucks, the average time it took to make a U-turn for two-wheelers was $4.98 \mathrm{~s}$, for three-wheelers $8.13 \mathrm{~s}$, for cars $11.69 \mathrm{~s}$, and $13.19 \mathrm{~s}$ for trucks, as summarized in Figure 5.

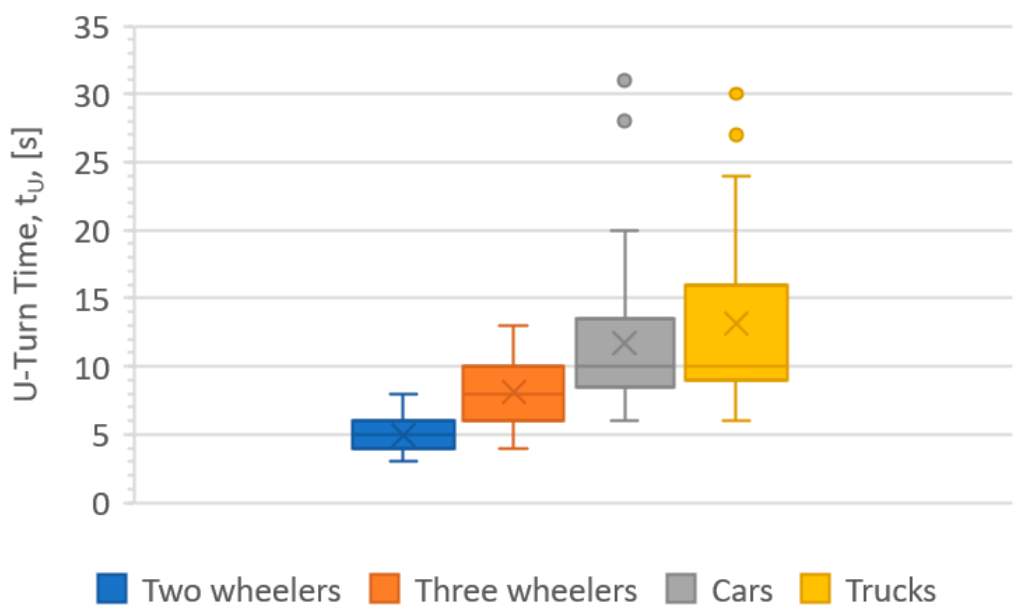

Figure 5. U-Turn times for different vehicle types. 
The figure suggests that the $t_{U}$ and its variability increases as the size of the vehicle increases. Similar findings were reported by Mohapatra et al. [8]. Outlier values of $t_{U}$ for cars and trucks show that, although happening rarely, significant turning times may occur while maneuvering the U-turn. It happens either when the driver starts turning at the wrong point, which leads to driving in reverse on the opposite lane to complete the turn, or when there is a parked vehicle on the opposite lane that restricts the driver's ability to complete the turn in one step.

\subsection{Traffic Volume}

The U-turning vehicles impede the traffic flow on the opposite lanes [10]. It is, therefore, important to monitor the flow of traffic volume in the opposite lanes during the U-turn maneuvers. To accomplish this, the recorded clips were analyzed for the traffic volume on each travel direction separately as suggested in the Highway Capacity Manual [22]. Each vehicle type passing through the study-site on the opposite lanes were tallied. The tally was carried out in passenger-car-per-hour-per-direction units (veh/h/2-lanes). The counts were recorded for 15 -min time periods, later adjusted to hourly volume units. Table 1 summarizes the opposite lane volumes.

Table 1. Traffic volumes for the four sets of video recording.

\begin{tabular}{ccccccc}
\hline & \multicolumn{7}{c}{ Traffic Volume } \\
\cline { 2 - 7 } Set & $\mathbf{2 w}$ & $\mathbf{3 w}$ & Cars & Trucks & [veh/h/2-Lanes] & [veh/s/2-Lanes] \\
\cline { 2 - 7 } & 417 & 73 & 104 & 40 & 1282 & 0.3561 \\
1 & 585 & 97 & 116 & 30 & 1557 & 0.4325 \\
2 & 510 & 107 & 97 & 30 & 1446 & 0.4017 \\
3 & 463 & 120 & 118 & 57 & 1643 & 0.4564 \\
\hline
\end{tabular}

Since two-wheeler vehicles have a different influence on the traffic flow than a passenger car vehicle, it is customary to express the impacts in singular-passenger-car units [23]. According to the urban road design specifications of Vietnam [21], it is suggested that in motorbike-dominated traffic, four motorcycles have the equivalent impact of one passenger car on the flow of traffic. Therefore, tallied values of two-wheelers were converted into passenger car units by a factor of 0.25 . The adjusted volumes, $V_{a d j}$, were calculated using Equation (5). A unit conversion factor was used for three-wheelers and for trucks since they have a similar projected area/space on the road as that of passenger cars (typical pickup truck length $520 \mathrm{~cm}$; three-wheelers vary 250-620 cm), and hence have a similar influence on the traffic volume.

$$
V_{a d j}\left(\frac{v e h}{h}\right)=4\left(\frac{15 \min }{h}\right) \times\left(0.25 \times V_{2 w}+V_{3 w}+V_{c a r}+V_{t r u c k}\right)
$$

where:

$V_{\text {adj }}$ : adjusted volume of vehicles per hour

$V_{2 w}$ : volume of the two wheelers per $15 \mathrm{~min}$

$V_{3 w}$ : volume of the three wheelers per $15 \mathrm{~min}$

$V_{\text {car }}$ : volume of the cars per $15 \mathrm{~min}$

$V_{\text {truck }}$ : volume of the trucks per 15 min

The traffic flow is a continuously changing parameter. Therefore, the corresponding flow values of each set were used when calculating the delay for the set, thus increasing the accuracy of the calculated delay.

\subsection{U-Turn Frequency}

The frequencies of U-turning vehicles were counted for each vehicle type throughout the recorded clips. In all four sets, the frequency of two-wheelers maneuvering the U-turn 
was the highest, followed by three wheelers, cars and, lastly, trucks. Table 2 summarizes the average of hourly recorded frequency values for each set.

Table 2. Frequency of the vehicle U-turns in a given hour.

\begin{tabular}{ccccc}
\hline Set & $\mathbf{2 w}$ & $\mathbf{3 w}$ & Cars & Trucks \\
\hline 1 & 190 & 30 & 30 & 12 \\
2 & 249 & 52 & 32 & 12 \\
3 & 212 & 56 & 32 & 12 \\
4 & 216 & 36 & 32 & 8 \\
\hline
\end{tabular}

\section{Results and Discussions}

Applying Equations (3)-(5) to the collected data given in Tables 1 and 2 reveals the results summarized in Table 3. The total delay for each set was calculated based on the delay data of each type of vehicle. Notice that the two-wheelers' delay is assumed to contribute only a quarter of that of the other types of vehicles [23]. Delay per vehicle was evaluated by dividing the total delay, $T D$, by the adjusted volume, $V_{a d j}$, of the traffic on the opposite direction. Thus, the delay per vehicle represents the average delay experienced by all vehicles travelling on the opposite lanes through the location.

Table 3. Calculated delay by vehicle type, total delay and delay per vehicle.

\begin{tabular}{ccccccc}
\hline & \multicolumn{5}{c}{ Delay Due to Type, $\boldsymbol{D}_{\boldsymbol{i}}[\mathbf{v e h} \times \mathbf{s}]$} & \\
\cline { 2 - 4 } Set & $\mathbf{2 w}$ & $\mathbf{3 w}$ & Cars & Trucks & Total Delay, $\boldsymbol{T D}$ [veh $\times \mathbf{s}]$ & Delay/Vehicle [s/veh] \\
\hline 1 & 1535 & 673 & 1378 & 1075 & 3510 & 2.74 \\
2 & 2749 & 1522 & 1637 & 969 & 4816 & 3.09 \\
3 & 2152 & 1522 & 1538 & 753 & 4351 & 3.01 \\
4 & 2547 & 1088 & 2728 & 365 & 4817 & 2.93 \\
\hline
\end{tabular}

The evaluated delay per vehicle parameter can be regarded as the most important finding of this study. The results suggest that, on average, each vehicle on the opposite lanes passing by the U-turning location is delayed by about three seconds (delay/vehicle $\operatorname{avg}=2.94 \mathrm{~s}$ ). In other words, under conditions that are similar to the testing conditions, each U-turn median opening on the road extends the travel time for all vehicles by about three seconds. Considering the average speed of the traffic flow at the studied area, which is $35.2 \mathrm{~km} / \mathrm{h}$, the U-turns cause about $28.8 \mathrm{~m}$ less distance travelled for each vehicle compared to U-turn restricted locations. This corresponds to an average speed reduction of about $11 \mathrm{~km} / \mathrm{h}$ or $31.3 \%$ for each vehicle travelling the studied stretch of the road.

According to the Highway Capacity Manual [22], the performance of the investigated road section with a traffic volume of 640 to 820 passenger-cars-per-hour-per-lane and the travel speeds of $32.5 \mathrm{~km} / \mathrm{h}$ corresponds to a level of service of E (LOS E). Considering the finding of this study of $11 \%$ speed reduction due to the U-turning maneuvers at the medians, the level of service at these segments of the roads reduces to an unacceptable level of F (LOS F).

From the table, it can also be seen that two-wheelers and three wheelers contribute the least delay, despite having higher turning frequencies (please note that the delay of two wheelers should be assumed to be $25 \%$ of the values in the table). On the other hand, U-turning passenger cars contributed the most in all four sets. They accounted for more than $30 \%$ of the delay caused at the location, and in the fourth set contributed more than $50 \%$ of all of the delay. This can be explained by the relatively difficult turning maneuver of the vehicles due to their physical size. Whereas, two and three wheelers are much maneuverable compared to cars, and, hence, lower delays are caused. Trucks would also have contributed significantly had there been a comparable number of U-turning trucks. 


\section{Conclusions}

Traffic congestion in Phnom Penh has been a chronic problem for the sustainable development of the transportation system. Among many others, traffic delays are one of the most significant consequences of traffic congestion. Significant traffic delay can be caused by the U-turning vehicles at the medians of road corridors where the maneuver is not restricted. This study provides a quantitative analysis of the traffic delay as experienced in Phnom Penh, Cambodia. A technique was developed to analyze the delay through recorded video clips which were used to extract traffic data for the analysis.

The results suggest that there is a significant correlation between the traffic delay and the U-turning vehicles at uncontrolled medians. According to the findings of the study, U-turning passenger cars caused the highest delay, while two- and three-wheelers contributed relatively less delay. One of the most important findings of the study is that the average delay caused by the U-turning vehicles on each through-travelling vehicle on the opposite direction is about three seconds. This finding reveals profound implications related to the influence of U-turning vehicles on the flow of traffic. It shows that, under conditions that are similar to the tested conditions, at each unrestricted U-turn median each vehicle travelling through the section on the opposite lane is delayed for about three seconds. This affects travel times and, thus, traffic congestion in the corridor considerably. Therefore, to achieve less delay and shorter travel times, uncontrolled U-turning maneuvers should be restricted at medians of road corridors as much as possible.

The findings shed light on the importance of U-turn maneuvers, which is not only in terms of causing traffic congestion, but also the consequences that affect the sustainability performance of the transportation system in Phnom Penh. Similarly, in many other countries, inconvenience, and economic losses to drivers, as well as air pollution are among the most detrimental consequences of the traffic delays (because of the U-turns) in the city.

Despite the limitations of the study, such as data collected from only one U-turning point or the assumptions made to evaluate the single delay, the results consistently indicate strong evidence about experienced delay due to U-turns at medians resulting in added traffic congestion. To verify and to better understand the phenomenon, further analysis at different locations with different traffic volumes should be performed. New developments in research, especially in the field of machine learning, may offer a better understanding and evaluation of the delays due to U-turns. A few but consistent results from this study suggest that comparable results are likely to be witnessed.

Author Contributions: Conceptualization, methodology, formal analysis, data curation, visualization, M.O.; writing-original draft preparation, M.O., S.I. and S.D.; writing-review and editing, M.O., S.I., S.D. and W.N.M.W.M.R.; supervision, S.I. and W.N.M.W.M.R. All authors have read and agreed to the published version of the manuscript.

Funding: This paper was financed by the grants under Cost Centre No. Q.K130000.3556.07G00 and Q.K130000.3656.03M21 of the Research Management Centre (RMC) and Razak Faculty of Technology and Informatics (RFTI) of Universiti Teknologi Malaysia (UTM).

Data Availability Statement: Data presented in this study is available upon request to the corresponding author.

Acknowledgments: The authors would also like to express their sincere gratitude to the Ministry of Education, Malaysia and both the Research Management Centre (RMC) and Razak Faculty of Technology and Informatics (RFTI) of Universiti Teknologi Malaysia (UTM), for providing financial support.

Conflicts of Interest: The authors declare no conflict of interest. 


\section{References}

1. Thomas, N.A.; Weber, K.A. The Environmental Impact of Logistics: Evaluating and Reducing the Environmental Impact of Transportation and Warehousing by Using the Example of a Pharmaceutical Company. Ph.D. Thesis, MIT, Cambridge, MA, USA, 2016.

2. Ziyadi, M.; Ozer, H.; Kang, S.; Al-Qadi, I.L. Vehicle energy consumption and an environmental impact calculation model for the transportation infrastructure systems. J. Clean. Prod. 2018, 174, 424-436. [CrossRef]

3. Rodrigue, J.P.; Comtois, C.; Slack, B. The Geography of Transport Systems, 5th ed.; Routledge: New York, NY, USA, 2016 ; Chapter 4.

4. Japan International Cooperation Agency. The Project for Comprehensive Urban Transport Plan in Phnom Penh Capital City (PPUTMP), Final Report Executive Summary. JICA 2014. Available online: https:/ / openjicareport.jica.go.jp/pdf/12245833.pdf (accessed on 23 November 2021).

5. Baker, J.L.; Natsuoko, K.; Xinyuan, S.L.; Johnson, E.C.; Yin, S.; Ou, N. Urban Development in Phnom Penh; World Bank Group: Washington, DC, USA, 2017.

6. Jenjiwattanakul, T.; Sano, K.; Nishiuchi, H. Operation Performance of Police Control at U-turn. In Energy and Environments; The 3rd International Symposium on Engineering; Siam University: Bangkok, Thailand, 2013.

7. Mohanty, M.; Dey, P.P. Modelling the major stream delay due to U-turns. Transp. Lett. 2019, 11, 498-505. [CrossRef]

8. Mohapatra, S.S.; Dey, P.P.; Chandra, S. Modeling the critical position of U-turning vehicles at uncontrolled median openings. KSCE J. Civ. Eng. 2016, 20, 411-420.

9. El Esawey, M.; Sayed, T. Operational performance analysis of the unconventional median U-turn intersection design. Can. J. Civ. Eng. 2011, 38, 1249-1261.

10. Mohanty, M.; Dey, P.P.; Mishra, A. Reduction in flow due to U-turns at median openings. Transp. Res. Board 96th Annu. Meet. 2017, 17, 195.

11. Pirdavani, A.; Brijs, T.; Bellemans, T.; Wets, G. Travel time evaluation of a U-turn facility: Comparison with a conventional signalized intersection. Transp. Res. Rec. 2011, 2223, 26-33. [CrossRef]

12. Liu, P.; Lu, J.J.; Fan, J.; Pernia, J.C.; Sokolow, G. Effects of U-turns on capacities of signalized intersections. Transp. Res. Rec. 2005, 1920, 74-80. [CrossRef]

13. He, M.; Liu, L.; Wei, H.; Dong, R. Characteristics of Signalized U-Turn Movements in Headway Distribution, Capacity, and Control Delay: Case Study of Intersections in Kunming, China. Presented at the Transportation Research Board 88th Annual Meeting, Washington, DC, USA, 11-15 January 2009.

14. Alam, M.J.B.; Osra, K.A.; Al-Bar, H.O.; Zahran, S.Z. Signalized Intersection Capacity Adjustment Factors for Makkah, Saudi Arabia. Can. J. Transp. 2011, 4, 55-66.

15. Lu, W.; Vandebona, U.; Kiyota, M.; Wang, Y. Estimation of Traffic Delay at an Unconventional Roundabout by Computer Simulation. In Proceedings of the 2020 IEEE 3rd International Conference on Information Systems and Computer Aided Education (ICISCAE), Dalian, China, 27-29 September 2020; pp. 295-302.

16. Bagdatli, M.E.C.; Dokuz, A.S. Vehicle delay estimation at signalized intersections using machine learning algorithms. Transp. Res. Rec. 2021, 2675, 110-126. [CrossRef]

17. Lubna, T.; Mahmud, I.; Kim, G.H.; Cho, Y.Z. D-OLIA: A Hybrid MPTCP Congestion Control Algorithm with Network Delay Estimation. Sensors 2021, 21, 5764. [CrossRef] [PubMed]

18. AASHTO. Transportation Glossary; American Association of State Highway and Transportation Officials: Washington, DC, USA, 2009,

19. Webster, F. Traffic Signal Settings; Road Research Paper No.39; Road Research Laboratory, Her Majesty's Stationery Office: London, UK, 1958.

20. Garber, N.J.; Hoel, L.A. Transportation Capacity Analysis in Traffic E Highway Engineering; Cengage Learning: Stamford, CT, USA, 2009; pp. 85-134.

21. TCXDVN104-2007; Urban Roads Specifications for Design; Hanoi, Vietnam, 30 May 2007. Available online: https:/ /pdfcoffee. com/standardtcxdvn-104-2007urban-roadenpdf-pdf-free.html (accessed on 23 November 2021).

22. Manual, Highway Capacity, HCM2010. Transportation Research Board; National Research Council: Washington, DC, USA, 2010.

23. Minh, C.C.; Sano, K.; Mai, T.T.; Matsumoto, S. Development of Motorcycle Equivalent Unit (MCU) For Motorcycle-Dominated Traffic. J. East. Asia Soc. Transp. Stud. 2010, 8, 1596-1608. 